\title{
Qualidade fisiológica de sementes de araçazeiro durante o armazenamento
}

\author{
Roberta A. Cisneiros ${ }^{1}$, Valderez P. Matos ${ }^{2}$, Margarida A. Lemos ${ }^{3}$,
} Odemar V. dos Reis ${ }^{4}$ \& Rosilda de M. Queiroz ${ }^{5}$

\begin{abstract}
1 Professora da UPE. Fone: (81) 3439-5066, Fax: (81) 3445-2093. E-mail: rosilda@biogate.com (Foto)
2 Depto. de Agronomia da UFRPE. R. Dom Manoel de Medeiros s/n, CEP 52171-950, Recife, PE. Fone: (81) 3302-1245. E-mail: vpontesmatos@bol.com.br

3 Programa de Pós-graduação em Botânica da UFRPE

${ }^{4}$ Empresa Pernambucana de Pesquisa Agropecuária (IPA). Av. Gal. San Martin 1371, Bonji, CEP 50761-000, Recife, PE

${ }^{5}$ Depto. de Biologia da UFRPE. R. Dom Manuel de Medeiros s/n, CEP 52171-030, Recife, PE. Fone: (81) 3445-0596, Fax: (81) 3445-2093. E-mail: rosilda@biogate.com
\end{abstract}

Protocolo 168 - 28/11/2001 - Aprovado em 26/9/2003

Resumo: O presente trabalho teve como objetivo avaliar diferentes ambientes de armazenamento e embalagens quanto à eficiência na manutenção da qualidade das sementes de araçazeiro (Psidium guineense Swartz) durante 180 dias. As sementes foram provenientes de frutos recém-colhidos completamente maduros e de oito acessos do banco ativo de germoplasma do araçazeiro localizado na Estação Experimental de Itapirema, da Empresa Pernambucana de Pesquisa Agropecuária - IPA, Goiana, PE, assim denominados: IPA 4, IPA 6, IPA 7, IPA 9, IPA 10, IPA 11, IPA 15 e IPA 16. 0 experimento foi representado pelas combinações dos fatores: sementes de oito acessos do araçazeiro, acondicionadas nas embalagens saco de papel Kraft e vidro, armazenadas nos ambientes normal de laboratório e no freezer, em Recife, PE, durante 180 dias. A qualidade fisiológica das sementes foi avaliada no início e a cada 60 dias de armazenamento, através de germinação e vigor (primeira contagem e índice de velocidade de germinação) determinando-se também o teor de água das sementes. Os resultados permitiram concluir-se que as sementes dos acessos do araçazeiro tiveram sua qualidade fisiológica reduzida, com perdas significativas na germinação e vigor, no decorrer do armazenamento. A embalagem de vidro proporcionou maior eficiência na conservação da qualidade fisiológica das sementes, sob condição de alta umidade relativa no interior do freezer, condição esta que provocou maior deterioração das sementes acondicionadas em embalagens de papel Kraft. Dentre os ambientes de armazenamento estudados, o mais adequado para conservação das sementes de araçazeiro foi o ambiente normal de laboratório, para ambas as embalagens testadas. Os acessos IPA 4 e IPA 6 apresentaram os maiores índices de germinação e vigor.

Palavras-chave: Psidium guineense, germinação, vigor, conservação, embalagem

\section{Physiological quality of seeds of Psidium guineense Swartz during storage}

Abstract: The present work had the objective of evaluating different storage environments and packings in relation to the efficiency in the maintenance of the quality of the seeds of 'Araçá' (Psidium guineense Swartz), during 180 days. The seeds were obtained from fully ripened recentlyharvested fruits of eight accesses of the active germoplasm bank of the 'Araçazeiro' located in the Experimental Station of Agricultural Research Organization of the State of Pernambuco at Itapirema, Goiana-PE, and denominated as IPA 4, IPA 6, IPA 7, IPA 9, IPA 10, IPA 11, IPA 15 and IPA 16. The experiment was represented by the combinations of the following factors: seeds of 8 accesses of the 'Araçazeiro', conditioned in the Kraft paper bags and glass, stored under environmental conditions of Recife-PE, and in a freezer. The physiological quality of the seeds was evaluated at the beginning and at every 60 days of storage, through the germination and vigor (first count germination and index of germination speed). The results showed that the physiological quality of the seeds was reduced with significant losses in the germination and vigor during the storage period. The glass packing provided larger efficiency in the conservation of the physiological quality of the seeds, under conditions of high relative humidity inside the freezer, which provoked larger deterioration of the seeds conditioned in Kraft paper bags. Among the environment of storage tested, the most efficient in the conservation of the seeds of the 'Araçazeiro' was the storage under normal environmental condition for both packings. The accesses IPA 4 and IPA 6 presented the highest germination indexes and vigor.

Key words: Psidium guineense, germination, vigor, conservation, packing 


\section{INTRODUÇÃO}

O araçazeiro (Psidium guineense Swartz) apresenta potencial para exploração econômica devido à boa aceitação de seus frutos para consumo in natura, pelo elevado teor de vitamina $\mathrm{C}$, quatro vezes maior que as frutas cítricas, além da alta capacidade de frutificação, resistência a doenças e pragas (exceto à mosca das frutas) e dispersão, que indica adaptação a diferentes ambientes (Raseira \& Raseira, 1994). A propagação do araçazeiro dá-se predominantemente por sementes, uma vez que a propagação vegetativa não tem apresentado resultados satisfatórios (Nachtigal \& Fachinello, 1994).

A conservação do germoplasma é um fator altamente relevante dentro do contexto de um sistema de recursos genéticos (Ferreira, 1988) pois é através da conservação a curto, médio e longo prazos, que o material se torna disponível para a comunidade de usuários. $\mathrm{O}$ autor ainda enfatiza que o sucesso de um programa depende de um sistema adequado de conservação de germoplasma.

Em um banco de germoplasma, segundo Goedart (1988) é essencial se conhecer as características das sementes de cada espécie que se vai armazenar, assim como os procedimentos adequados para sua conservação e os métodos apropriados para determinar a viabilidade inicial e a monitoração da sua viabilidade durante o armazenamento no banco. Segundo Popinigis (1977) geralmente a longevidade é aumentada conservando-se a semente com baixo teor de umidade e baixa temperatura; dentre os fatores que alteram a preservação da semente, está o armazenamento, que envolve desde a embalagem para acondicionamento até as condições de ambiente onde as sementes são guardadas.

Tendo em vista a escassez de informações sobre frutíferas nativas, o presente trabalho propôs avaliar diferentes embalagens e ambientes de armazenamento quanto à eficiência na manutenção da qualidade das sementes de araçazeiro armazenadas, evitando perdas de valiosos recursos genéticos.

\section{MATERIAL E MÉTODOS}

As sementes de araçazeiro foram provenientes de frutos recém-colhidos e completamente maduros, de oito acessos do Banco Ativo de Germoplasma da Estação Experimental de Itapirema, da Empresa Pernambucana de Pesquisa Agropecuária - IPA, localizada no município de Goiana a 7³7’30” de latitude Sul e 34 $57^{\prime} 03^{\prime \prime}$ de longitude Oeste, na zona da mata norte do Estado de Pernambuco. A colheita dos frutos foi feita no mês de agosto de 1998; para tanto, foram selecionados os acessos de araçazeiro: IPA 4, IPA 6, IPA 7, IPA 9, IPA 10, IPA 11, IPA 15 e IPA 16, que apresentavam, na ocasião, as maiores produções de frutos.

Tomou-se cada acesso como integrante de uma população e se misturou igual quantidade de sementes de quatro plantas da mesma população, formando-se os bulks (oito bulks). As sementes, depois de retiradas dos frutos, foram postas para secar à sombra, durante cinco dias sendo, após este, período de secagem, efetuada a determinação do teor de água em estufa a $105 \pm 3^{\circ} \mathrm{C}$ por 24 horas, de acordo com Brasil (1992).
As sementes de cada acesso foram acondicionadas separadamente em sacos de papel Kraft e recipientes de vidro; os primeiros foram lacrados com fita adesiva e os recipientes de vidro foram vedados com parafina comum derretida. Esse material foi armazenado nos ambientes normal de laboratório (temperatura $26,5 \pm 1{ }^{\circ} \mathrm{C}$ e umidade relativa variando de 69,9 a $74,8 \%$ ) e de freezer (temperatura $-20^{\circ} \mathrm{C}$ e umidade relativa $90 \%$ ) durante 180 dias, no período de setembro de 1998 a março de 1999, em Recife, PE.

No início do armazenamento e a cada 60 dias, as sementes conservadas nos diferentes ambientes foram submetidas à determinação do teor de água e a testes de germinação e vigor, efetuados no Laboratório de Botânica da Universidade Federal Rural de Pernambuco, em Recife, PE.

Por apresentarem tegumento duro e impermeável e de acordo com testes preliminares, as sementes de araçazeiro foram submetidas ao tratamento pré-germinativo com ácido sulfúrico $\left(\mathrm{H}_{2} \mathrm{SO}_{4}\right)$ concentrado a $97 \%$ por $5 \mathrm{~min}$, após o qual foram lavadas em água corrente e imersas em solução de hipoclorito de sódio a $1 \%$, por $5 \mathrm{~min}$; depois, foram lavadas em água destilada e postas para germinar.

Para avaliação da qualidade inicial da semente e a cada 60 dias de armazenamento, foram realizados testes de germinação e vigor. $\mathrm{O}$ teste de germinação foi realizado utilizando-se quatro repetições de 50 sementes distribuídas sobre papel mata-borrão (germibox) e postas para germinar em caixas transparentes. Após a semeadura, elas foram mantidas em germinador, a temperatura de $25^{\circ} \mathrm{C}$. As avaliações foram feitas diariamente, anotando-se o número de plântulas normais.

Como testes de vigor foram considerados: a primeira contagem de germinação, avaliando-se o número de plântulas normais que apresentavam sistema radicular e parte aérea emergidos 20 dias após a instalação do teste padrão de germinação; o índice de velocidade de germinação (IVG), que consistiu na avaliação das plântulas diariamente, na mesma hora, a partir do dia em que surgiram as plântulas normais, prosseguindo até o dia da última contagem que ocorreu 32 dias após instalação do teste padrão de germinação, e com o número diário de plântulas normais, calculou-se a velocidade de germinação, empregando-se a fórmula recomendada por Maguire (1962) e citada por Nakagawa (1994).

O delineamento experimental para cada ambiente de armazenamento (normal de laboratório e freezer) foi em blocos casualizados, com arranjo fatorial 8x2x4 (acesso x embalagem $\mathrm{x}$ período). Realizaram-se análises conjunta de variância para os fatores acesso, embalagem e ambiente de armazenamento, sendo os valores em porcentagem transformados em arcsen $\sqrt{ } \mathrm{x} / 100$. As médias foram comparadas pelo teste de Tukey. Para períodos de armazenamento fez-se o estudo de regressão.

\section{RESULTADOS E DISCUSSÃO}

Quanto ao teor de água, as sementes armazenadas no freezer mostraram diferenças significantes entre as embalagens, o mesmo não ocorrendo em ambiente normal de laboratório (Tabela 1). Os teores de água mais elevados, em torno de 11,74\%, foram verificados nas sementes de araçazeiro armazenadas em sacos de papel Kraft no freezer, indicando que as sementes, 
por serem higroscópicas, e estas embalagens permitirem trocas de umidade com o meio, tendem a sofrer alterações em seu teor de água durante o período de armazenamento em ambiente úmido.

Tabela 1. Teor de água de sementes de araçazeiro acondicionadas em dois tipos de embalagem e em dois ambientes diferentes, durante 180 dias de armazenamento*

\begin{tabular}{lcc}
\hline \multirow{2}{*}{ Embalagens } & \multicolumn{2}{c}{ Umidade (\%) } \\
\cline { 2 - 3 } & $\begin{array}{c}\text { Ambiente Normal } \\
\text { de Laboratório }\end{array}$ & Freezer \\
\hline Saco de papel Kraft & $9,66 \mathrm{Ba}$ & $13,58 \mathrm{Aa}$ \\
Vidro & $9,76 \mathrm{Ba}$ & $9,86 \mathrm{Ab}$ \\
\hline $\mathrm{CV}(\%)$ & 3,70 & 11,52 \\
\hline
\end{tabular}

* Médias seguidas da mesma letra minúscula na coluna e da mesma letra maiúscula na linha não diferem significantemente pelo teste de Tukey a $5 \%$

As embalagens permeáveis, por permitirem trocas de vapor de água entre as sementes e o ar atmosférico, são mais empregadas em regiões de clima seco ou quando o período de armazenamento for relativamente curto; já as embalagens impermeáveis eliminam a influência de umidade do ar atmosférico sobre as sementes (Toledo \& Marcos Filho, 1979) e são mais empregadas em climas úmidos ou quando o período de armazenamento for relativamente longo.

Relacionando-se a umidade relativa nos dois ambientes de armazenamento, verifica-se que no ambiente normal de laboratório a umidade relativa variou de 70 a $74,8 \%$, enquanto no freezer ficou em torno de $90 \%$. O conhecimento do teor de água das sementes é essencial para se determinar as condições adequadas para o armazenamento, uma vez que o mesmo é função direta da umidade relativa e esta é influenciada pela temperatura do ambiente e pelo tipo de embalagem (Warhm, 1996).

A germinação inicial foi de $60 \%$, porém, ao longo do armazenamento, o poder germinativo das sementes armazenadas em ambiente normal de laboratório decresceu gradativamente, alcançando um valor mínimo de $47 \%$ aos 180 dias (Fig. 1A). Nas sementes armazenadas no freezer verificou-se redução acentuada do poder germinativo que, aos 60 dias, foi igual a $23 \%$ (Fig. 1A) e pequena redução a partir desse período. A mesma tendência dos resultados foi verificada em relação ao percentual da primeira contagem de germinação (Fig. 1B) e ao índice de velocidade de germinação (Fig. 1C).

Esses resultados sugerem que, para as sementes de araçazeiro, o armazenamento em ambiente normal de laboratório é mais indicado que no freezer. Durante o armazenamento em ambiente normal de laboratório, a umidade relativa do ar variou de 69,9 a $74,8 \%$, enquanto no freezer ficou em torno de $90 \%$. Freitas et al. (1992) relataram que a condição de alta umidade relativa no interior da câmara provoca maior deterioração das sementes quando são acondicionadas em embalagens de alta permeabilidade. Segundo os autores, sementes acondicionadas em embalagens impermeáveis, apesar de manterem baixos os teores de água, também apresentam sinais de deterioração. Lima et al. (1991) trabalhando com sementes de maracujazeiro (Passiflora edulius Sims) informaram que o período de viabilidade dessas sementes não é superior a um ano e que o

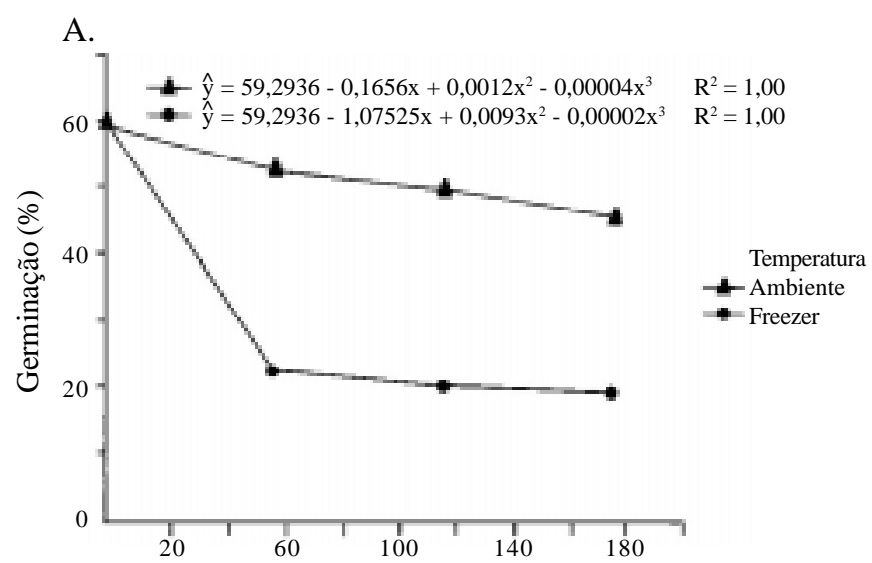

B.
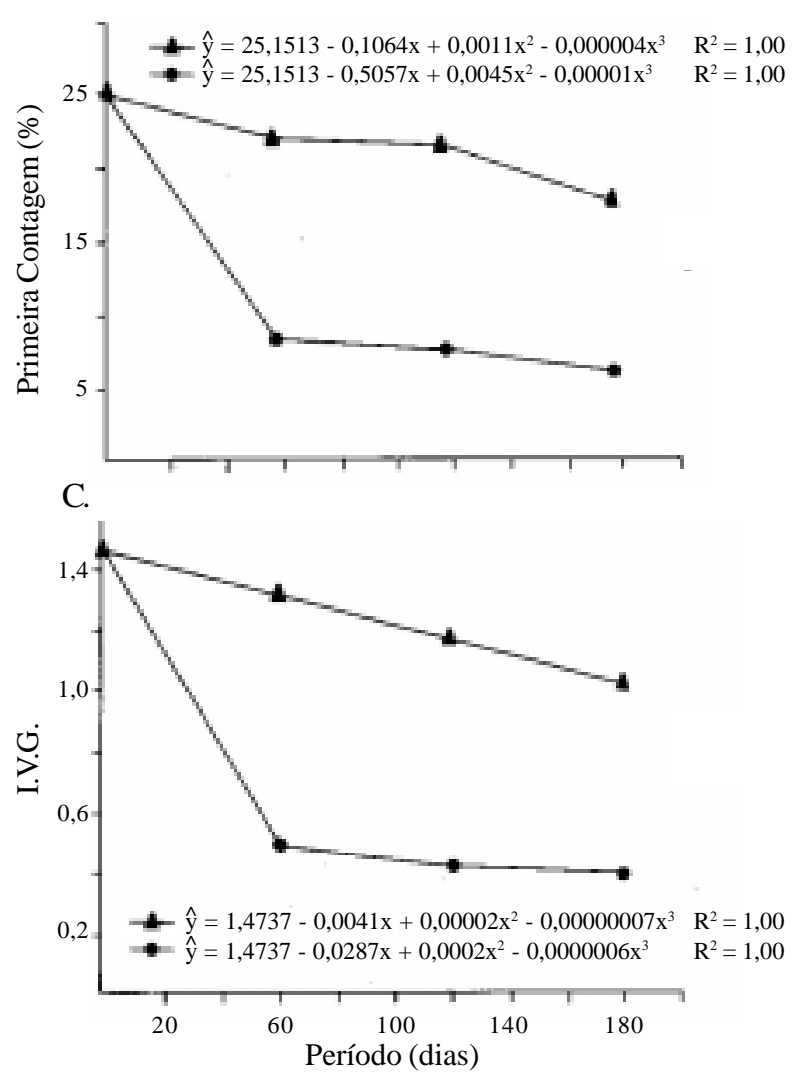

Figura 1. Porcentagem de germinação (A), porcentagem de primeira contagem $(\mathrm{B})$ e velocidade de germinação $(\mathrm{C}) \mathrm{de}$ sementes de araçazeiro (Psidium guineense), armazenadas à temperatura ambiente (em ambiente normal de laboratório) e no freezer, durante 180 dias de armazenamento

período de armazenamento e o ambiente de conservação influem efetivamente sobre a capacidade de emergência e vigor das sementes.

Na Tabela 2 verifica-se que as embalagens utilizadas não proporcionaram diferenças significativas nos valores médios da capacidade de germinação das sementes armazenadas em ambiente normal de laboratório. Por outro lado, constatou-se efeito significativo do ambiente de armazenamento, sendo os valores obtidos para as sementes mantidas no ambiente normal de laboratório superiores aos das mantidas no freezer. Para essas últimas, a redução na viabilidade da semente foi mais pronunciada na embalagem de papel Kraft. Esta embalagem, 
Tabela 2. Qualidade fisiológica das sementes dos acessos de araçazeiro acondicionadas em dois tipos de embalagens e armazenadas em dois ambientes diferentes, durante180 dias*

\begin{tabular}{|c|c|c|c|c|c|c|}
\hline \multirow{2}{*}{ Embalagem } & \multicolumn{2}{|c|}{ Germinação (\%) } & \multicolumn{2}{|c|}{$1^{\mathrm{a}}$ Contagem $(\%)$} & \multicolumn{2}{|c|}{$\begin{array}{c}\text { Índice de Velocidade } \\
\text { de Germinação }\end{array}$} \\
\hline & $\begin{array}{l}\text { Ambiente Normal } \\
\text { de Laboratório }\end{array}$ & Freezer & $\begin{array}{l}\text { Ambiente Normal } \\
\text { de Laboratório }\end{array}$ & Freezer & $\begin{array}{l}\text { Ambiente Normal } \\
\text { de Laboratório }\end{array}$ & Freezer \\
\hline Saco de papel Kraft & $52,76 \mathrm{Aa}$ & $14,82 \mathrm{Bb}$ & $21,73 \mathrm{Aa}$ & $6,28 \mathrm{Bb}$ & $1,25 \mathrm{Aa}$ & $0,36 \mathrm{Bb}$ \\
\hline Vidro & $52,18 \mathrm{Aa}$ & $46,98 \mathrm{Ba}$ & $21,19 \mathrm{Aa}$ & $17,14 \mathrm{Ba}$ & $1,22 \mathrm{Aa}$ & $1,01 \mathrm{Ba}$ \\
\hline $\mathrm{CV}(\%)$ & 4,18 & 27,92 & 8,64 & 30,20 & 6,41 & 28,18 \\
\hline
\end{tabular}

Médias seguidas da mesma letra minúscula na coluna e da mesma letra maiúscula na linha não diferem significantemente pelo teste de Tukey a $5 \%$

por sua vez, não proporcionou germinação satisfatória em sementes armazenadas no freezer, enquanto que as sementes acondicionadas na embalagem de vidro demonstraram melhores resultados de porcentagem de germinação. A embalagem de vidro funcionou como uma barreira para as trocas entre as sementes e o ambiente e, conseqüentemente, reduzindo o metabolismo e retardando, desta forma, o processo de deterioração.

Esses resultados estão de acordo com as considerações de Harrington (1973), de que no armazenamento a temperaturas abaixo de zero, ocorre alta umidade relativa e, após um período de armazenamento, as sementes ganham umidade e cristais de gelo se formam nas camadas superficiais da semente, danificando-as, causando perda de viabilidade. Segundo o mesmo autor, se as sementes são inicialmente secas e acondicionadas em embalagens impermeáveis, elas não ganharão umidade e sobreviverão por longo período de tempo armazenadas a temperatura abaixo de zero. De acordo com Carvalho \& Nakagawa (1983) o tipo de embalagem utilizada no acondicionamento de sementes assume relevante importância na preservação da sua viabilidade e vigor, e está diretamente relacionada às condições climáticas ou do ambiente, sob as quais as sementes serão armazenadas.

Quanto às embalagens testadas (Tabela 2) no freezer, o vidro demonstrou ser mais eficiente na manutenção do vigor (primeira contagem e índice de velocidade de germinação). A embalagem de papel Kraft reduziu acentuadamente o vigor da semente, possivelmente por ser uma embalagem permeável e devido à higroscopicidade que as sementes apresentam, possibilitou a troca de umidade com o ambiente, uma vez que o conteúdo de umidade da semente está sempre buscando o equilíbrio com a umidade relativa do ar. Como o alto teor de água da semente, aliado a altas temperaturas, acelera a deterioração (Delouche \& Potts, 1974) deve-se evitar embalagens permeáveis em ambientes de armazenamento com umidade relativa alta.

No que diz respeito ao ambiente de armazenamento, as sementes armazenadas no ambiente normal de laboratório germinaram mais rapidamente que aquelas armazenadas no freezer. Isto se deu provavelmente porque no armazenamento em ambiente normal de laboratório, o processo de deterioração das sementes ocorreu de forma lenta e gradual, não ocasionando queda brusca na velocidade de germinação das sementes.

A redução da velocidade de germinação das sementes armazenadas no freezer (Tabela 2) foi de quase $50 \%$, indicando mais uma vez que a temperatura de $-20^{\circ} \mathrm{C}$ não é a mais indicada para a conservação das sementes de araçazeiro. Talvez em temperaturas mais elevadas (de 0 a $10^{\circ} \mathrm{C}$ ), as sementes tivessem apresentado níveis de vigor também mais elevados. É interessante salientar que Farias Neto et al. (1991) trabalhando com sementes de cagaita (Eugenia dysenterica DC.), mirtácea frutífera do Cerrado, concluíram que a condição mais adequada para conservação das sementes, com menores perdas de viabilidade, foi a câmara fria a $10^{\circ} \mathrm{C}$. Koller et al. (1993) constataram que as temperaturas em torno de 2 a $5{ }^{\circ} \mathrm{C}$ possibilitaram boa conservação das sementes de citrus (Poncirus trifoliata) por um período de até um ano. Segundo Lima et al. (1991) as sementes de maracujá armazenadas em ambiente de refrigerador $\left(5\right.$ a $\left.10{ }^{\circ} \mathrm{C}\right)$ apresentaram os valores mais elevados de germinação e vigor.

Durante o armazenamento, as sementes de araçazeiro suportaram temperaturas abaixo de zero $\left(-20^{\circ} \mathrm{C}\right)$ em embalagem hermética (vidro) comportando-se como sementes ortodoxas. Isto concorda com Roberts \& King (1980) os quais afirmam que sementes ortodoxas, quando armazenadas a longo prazo, devem ser acondicionadas em recipientes herméticos a $-18{ }^{\circ} \mathrm{C}$ ou menos.

Conforme se observa na Tabela 3 , para as sementes armazenadas em ambiente normal de laboratório houve diferença significativa entre os acessos quanto à porcentagem de germinação. O poder germinativo das sementes dos acessos IPA 4, IPA 6, IPA 15 e IPA 16 foi superior ao dos demais. Quando o armazenamento foi feito no freezer, não ocorreu diferença significativa entre os acessos. Como afirmam Roberts \& Ellis (1984) mesmo em uma amostra de sementes geneticamente uniforme e armazenada em condições estáveis de ambiente, existe uma variação considerável na longevidade da semente. Entretanto, é importante ter sempre presente que o genótipo e as condições de produção de sementes, principalmente durante a maturação, colheita, secagem e beneficiamento, afetam o potencial de armazenamento e as condições de armazenamento modificam este potencial.

Quando armazenadas em ambiente normal de laboratório, as sementes do acesso IPA 4 apresentaram maior porcentagem de germinação na primeira contagem, indicando que as sementes deste acesso tiveram melhor desempenho germinativo que dos demais sendo, conseqüentemente, mais vigorosas; por outro lado, as dos acessos IPA 7, IPA 9 e IPA 11 demonstraram ser as menos vigorosas. Quando armazenadas no freezer, a variação entre os acessos foi menos acentuada e apenas o acesso IPA 9 foi inferior ao acesso IPA 4. 
Tabela 3. Qualidade fisiológica das sementes dos acessos de araçazeiro armazenadas à temperatura ambiente e no freezer, durante 180 dias de armazenamento*

\begin{tabular}{|c|c|c|c|c|c|c|}
\hline \multirow[b]{2}{*}{ Acesso } & \multicolumn{2}{|c|}{ Germinação (\%) } & \multicolumn{2}{|c|}{$1^{\mathrm{a}}$ Contagem $(\%)$} & \multicolumn{2}{|c|}{ Velocidade de Germinação (IVG) } \\
\hline & $\begin{array}{c}\text { Ambiente Normal } \\
\text { de Laboratório }\end{array}$ & Freezer & $\begin{array}{l}\text { Ambiente Normal } \\
\text { de Laboratório }\end{array}$ & Freezer & $\begin{array}{l}\text { Ambiente Normal } \\
\text { de Laboratório }\end{array}$ & Freezer \\
\hline IPA 4 & $54,40 \mathrm{a}$ & $34,80 \mathrm{a}$ & $28,77 \mathrm{a}$ & $15,66 \mathrm{a}$ & $1,49 a$ & $0,87 \mathrm{a}$ \\
\hline IPA 6 & $58,74 \mathrm{a}$ & $35,64 \mathrm{a}$ & $23,34 b$ & $13,46 \mathrm{ab}$ & $1,46 \mathrm{a}$ & $0,86 \mathrm{a}$ \\
\hline IPA 7 & $42,64 \mathrm{c}$ & $25,50 \mathrm{a}$ & $14,86 \mathrm{c}$ & $8,96 a b$ & $0,86 \mathrm{e}$ & $0,50 \mathrm{ab}$ \\
\hline IPA 9 & $46,00 \mathrm{c}$ & $22,63 a$ & $14,49 \mathrm{c}$ & $7,49 \mathrm{~b}$ & $0,96 \mathrm{de}$ & $0,41 b$ \\
\hline IPA 10 & $51,41 \mathrm{~b}$ & $30,86 a$ & $23,63 b$ & $12,68 \mathrm{ab}$ & $1,24 \mathrm{c}$ & $0,71 \mathrm{ab}$ \\
\hline IPA 11 & $50,80 \mathrm{~b}$ & $28,89 \mathrm{a}$ & $17,13 \mathrm{c}$ & $8,93 \mathrm{ab}$ & $1,8 \mathrm{~d}$ & $0,57 \mathrm{ab}$ \\
\hline IPA 15 & $56,94 \mathrm{a}$ & $32,58 \mathrm{a}$ & $25,58 b$ & $11,97 \mathrm{ab}$ & $1,42 \mathrm{ab}$ & $0,75 \mathrm{ab}$ \\
\hline IPA 16 & $55,80 \mathrm{a}$ & $36,29 \mathrm{a}$ & $23,90 \mathrm{~b}$ & $14,53 \mathrm{ab}$ & $1,33 \mathrm{bc}$ & $0,86 \mathrm{a}$ \\
\hline $\mathrm{CV}(\%)$ & 4,18 & 27,92 & 8,64 & 30,20 & 6,41 & 28,18 \\
\hline
\end{tabular}

" Médias seguidas por letras distintas, na coluna, diferem pelo teste de Tukey a $5 \%$ de probabilidade

Ao se comparar o índice de velocidade de germinação entre as sementes armazenadas no ambiente normal de laboratório (Tabela 3) nota-se que as sementes dos acessos IPA 4 e IPA 6 apresentaram maior vigor, não diferindo, no entanto, do acesso IPA 15. Os menores valores foram obtidos nos acessos IPA 7, IPA 9 e IPA 11. Esses resultados de vigor apresentaram comportamento similar aos da capacidade de germinação, concordando com Freitas et al. (1992) quando afirmam que o nível de vigor influi sobre o processo de germinação.

Quanto ao vigor das sementes armazenadas no freezer, pode-se afirmar que houve comportamento semelhante dos acessos IPA 4, IPA 6 e IPA 16, que apresentaram maiores índices de velocidade de germinação em relação ao IPA 9. Neste ambiente de armazenamento ocorreu variação entre os acessos, embora em menor intensidade, o que não foi observado para a percentagem de germinação, que não detectou diferença significativa entre os acessos armazenados no freezer.

Segundo Vieira \& Carvalho (1994) a velocidade de germinação é um dos conceitos mais antigos de vigor de sementes. Lotes de sementes com porcentagens de germinação semelhantes, freqüentemente mostram diferenças em suas velocidades de germinação, indicando que existem diferenças de vigor entre eles, isto é, que há uma relação direta entre a velocidade de germinação e o vigor das sementes (Krzyzanowkski et al., 1999).

\section{CONCLUSÕES}

1. As sementes de araçazeiro apresentaram perdas de germinação e vigor ao longo do armazenamento, sendo o decréscimo mais acentuado no freezer.

2. A embalagem de vidro proporcionou maior eficiência na conservação da qualidade fisiológica das sementes, sob condição de alta umidade relativa no interior do freezer, condição esta que provocou maior deterioração das sementes acondicionadas em embalagens de papel Kraft.

3. Dentre as condições de armazenamento estudadas, a mais adequada para a conservação de sementes de araçazeiro, com as menores perdas de viabilidade, foi o ambiente normal de laboratório, utilizando tanto a embalagem saco de papel Kraft como o vidro.

4. As sementes de araçazeiro podem ser conservadas em temperaturas subzero, sendo consideradas ortodoxas.

5. Para futuros estudos visando maximizar a exploração do araçazeiro, são indicados os acessos IPA 4 e IPA 6.

\section{LITERATURA CITADA}

BRASIL. Ministério da Agricultura e da Reforma Agrária. Regras para análise de sementes. Brasília: SNDA/DNDV/ CLAV, 1992.365p.

Carvalho, N.M.; Nakagawa, J. Sementes: ciência, tecnologia e produção. Campinas: Fundação Cargil, 1983. 429p.

Delouche, J.C.; Potts, H.C. Programa de sementes: planejamento e implantação. Brasília: AGIPLAN, 1974. 118p.

Farias Neto, A.L.; Fonseca, C.E.L.; Gomide, C.C.C. Armazenamento de sementes de cagaita (Eugenia dyzenterica D.C.). Revista Brasileira de Fruticultura, Cruz das Almas, v.13, n.2, p.55-62, 1991.

Ferreira, R.F. Conservação de germoplasma In Vivo. In: Encontro sobre Recursos Genéticos, 2, 1988, Jaboticabal. Anais.... Jaboticabal, FCAV, 1988. p.96-101.

Freitas, G.B.; Silva; R.F.; Araújo, E.F. Influência da condição de armazenamento na qualidade de sementes de milho. Revista Brasileira de Armazenamento, Viçosa, MG. v.17, n.1, p.2126, 1992.

Goedart, C.O. Conservação de germoplasma semente. In: Encontro sobre Recursos Genéticos, 2, 1988, Jaboticabal. Anais.... Jaboticabal, FCAV, 1988. p.78-98.

Harrington, J.C. Seed storage and longevity. In: Kozlowski, T. T. Seed biology. London: Academic Press, 1973. 350p.

Koller, O.L.; Stuker, H.; Verona, L.A.F. Efeito da umidade da semente, temperatura de estocagem e da duração de estocagem sobre a germinação de Ponsirus trifoliata e de outros porta-enxertos de citrus. Revista Brasileira de Fruticultura, Cruz das Almas, v.15, n.1, p.27-33, 1993.

Krzyzanowski, F.C; Vieira, R.D.; França Neto, J.B. Vigor de sementes: conceitos e testes. Londrina: ABRATES, 1999. $218 \mathrm{p}$. 
Lima, D.; Bruno, R.L.A.; Lima, A.A. Efeitos de recipientes e de dois ambientes de armazenamento sobre a germinação e vigor de sementes de maracujazeiro amarelo. Revista Brasileira de Fruticultura, Cruz das Almas, v.13, n.2, p.27-32, 1991.

Nachtigal, J.C.; Fachinello, J.C. Efeito da época de coleta das estacas de araçazeiro. In: Congresso Brasileiro de Fruticultura, 13, 1994, Salvador, 1994. Resumos... Salvador: SBF, 1994. v.3, p.993.

Nakagawa, J. Testes de vigor baseados no desempenho das plântulas. In: Vieira, R.D.; Carvalho, N.M. (eds.) Testes de vigor em sementes. Jaboticabal: FUNEP, 1994. p.49-85.

Popinigis, F. Fisiologia de sementes. Brasília: AGIPLAN, 1977. 189 p.

Raseira, A.; Raseira, M. C.B. "Ya - cy", Cultivar de araçazeiro lançada pela EMBRAPA / CPACT. Hirti Sul, Pelotas, v.3, n.1, p.37-39, 1994.
Roberts, E.; King, M.W. The characteristics of recalcitrant seeds. In: Chin, H.F.; Roberts, E. H. (ed.). Recalcitrant crop seeds. Kuala Lumpur: Tropical Press, 1980. p.1-5.

Roberts, E.H.; Ellis, R.H. The implication of the deterioration of orthodox seeds during storage for genetic resources conservation. In: Holden, J.H.W.; Williams, J.T. (eds.) Crop genetic resources conservation and evaluation. London: IBPGR,. 1984. p.42-53.

Toledo, F.F.; Marcos Filho, J. Manual de sementes: tecnologia da produção. São Paulo: Agronômica Ceres, 1979. 224p.

Vieira, R.D.; Carvalho, M.M. Testes de vigor em sementes. Jaboticabal: FUNEP, 1994. 164p.

Warhm, E.J.A. Comparison of packing materials for seed with particular reference to humid environments. Seed Science and Technology, Zürich, v.14, n.1, p-191-211, 1986. 